\title{
Multiple effects of prefrontal lesions on task-switching
}

\author{
Tim Shallice ${ }^{1,2}$, Donald T. Stuss ${ }^{3,4, *}$, Terence W. Picton ${ }^{3,4}$, Michael P. Alexander ${ }^{5,6}$ \\ and Susan Gillingham ${ }^{4}$
}

1. Institute of Cognitive Neuroscience, University College London, London, UK

2. Cognitive Neuroscience Sector, SISSA, Trieste, Italy

3. Departments of Psychology and Medicine, University of Toronto, Toronto, ON, Canada

4. Rotman Research Institute at Baycrest, Toronto, ON, Canada

5. Harvard Medical School, Boston, MA, USA

6. Behavioral Neurology Unit, Beth Israel Deaconess Medical Center, Boston, MA, USA

Edited by: Robert T. Knight, University of California Berkeley, USA

Reviewed by: Marcel Brass, Ghent University, Belgium

Leon Y. Deouell, The Hebrew University of Jerusalem, Israel

\begin{abstract}
This study examined the performance of 41 patients with focal prefrontal cortical lesions and 38 healthy controls on a task-switching procedure. Three different conditions were evaluated: single tasks without switches and two switching tasks with the currently relevant task signalled either 1500 ms (Long Cue) or 200 ms (Short Cue) before the stimulus. Patients with Superior Medial lesions showed both a general slowing of reaction time (RT) and a significantly increased switch cost as measured by RT. No other prefrontal group showed this increased reaction time switch cost. Increased error rates in the switching conditions, on the other hand, were observed in patients with Inferior Medial lesions and, to a lesser extent, ones with Superior Medial lesions. Patients with left dorsolateral lesions (9/46v) showed slower learning of the task as indicated by a high error rate early on. Several different processes are involved in task-switching and these are selectively disrupted by lesions to specific areas of the frontal lobes.
\end{abstract}

Keywords: task-switching, switch-cost, anterior attentional system, frontal lobes, focal lesions, reaction time, errors

\section{INTRODUCTION}

Many tests used for assessing impairments of prefrontal function such as the Wisconsin Card-Sorting test (Milner, 1963; Stuss et al., 2000) and the Extra-Dimensional/Intra-Dimensional Shift task of the CANTAB battery (Owen et al., 1990) require the subject to switch from one 'task-set' or cognitive 'schema' to another. However, the extent to which the critical process of set-switching does in fact involve prefrontal cortex cannot be clearly determined from performance on these multi-component tests. In the mid-1990s, a paradigm was developed to allow switching from one cognitive schema to another to be examined in a purer form (Allport et al., 1994; see also Jersild, 1927; Meiran, 1996; Rogers and Monsell, 1995; Spector and Biederman, 1976). In this switching paradigm the subject must switch repeatedly, typically between two tasks, each of which can be carried out on the same stimuli. In the most frequently used variant, switches occur on a fixed schedule, e.g., the 'alternating runs' procedure developed by Rogers and Monsell (1995), wherein switches occur every two trials. This allows performance on so-called 'switch' trials to be contrasted with the equally common 'repeat' trials. Alternatively, the relevant task on each trial can be determined by a cue

*Correspondence: Donald T. Stuss, Rotman Research Institute, Baycrest 3560 Bathurst Street, Toronto, ON, M6A 2E1, Canada; Departments of Psychology and Medicine, University of Toronto, Toronto, ON, M5S 1A6, Canada. e-mail: dstuss@rotman-baycrest.on.ca Received: 31 August 2007; paper pending published: 29 November 2007; accepted: 02 February 2008; published online: 28 March 2008.

Citation: Front. Hum. Neurosci. (2008) 1: 2. doi: 10.3389/neuro.09.002.2007

Copyright $\odot 2008$ Shallice, Stuss, Picton, Alexander and Gillingham. This is an openaccess article subject to an exclusive license agreement between the authors and the Frontiers Research Foundation, which permits unrestricted use, distribution, and reproduction in any medium, provided the original authors and source are credited. occurring shortly before the stimulus, as in the task-cueing paradigm (Biederman, 1972; Meiran, 1996; Meiran and Daichman, 2005; Meiran et al., 2000).

These early studies led to the development of two contrasting hypotheses which have continued to dominate the field. In one, put forward by Rogers and Monsell (1995), switching between tasks requires a specific top-down process called 'task-set reconfiguration', which can be measured by the so-called 'Switch Cost', namely the average reaction time on a switch trial minus that on a repeat trial. A different account is given by Allport et al. (1994) who hold that the longer reaction times on switch than on repeat trials derive from the processing necessary to inhibit the task-set active on the previous trial; in this case the switch cost does not directly reflect the time that any particular operation takes (see also Gilbert and Shallice, 2002). More recently, Monsell (2003) has developed an intermediate position and differentiated three types of processes that affect task switching. First, following Allport et al. (1994) is 'task-set inertia', which has to be overcome. Second, is the equivalent of task-set reconfiguration, which Monsell called 'endogenous control', where the controlling task-set is switched in a top-down manner. Third, following a clear demonstration of the potency of the process by Allport and Wylie (2000), is 'exogenous task-set' activation, where the activation is generated directly from associations previously made with the specific stimuli (see also Waszak et al., 2003). The second and third of these correspond to the two ways of activating schema in the model of Norman and Shallice (1986) - through topdown activation from the supervisory attention system and by bottom-up triggering by incoming sensory information in contention scheduling.

Several neuropsychological studies have suggested that lesions of the left prefrontal cortex affect task-set switching (Aron et al., 2004; Keele and Rafal, 2000; Mecklinger et al., 1999; Rogers et al., 1998; Stablum et al., 1994). Rogers et al. (1998) studied six patients with left 
frontal lesions and six with right frontal lesions. Only the patients with left frontal lesions showed larger switch costs than controls. However, these extra switch costs only occurred when the tasks were potentially interfering (or 'incongruent') - the two task-sets active in the same block requiring different responses to the same stimuli - and indeed a similar effect has recently been obtained in patients with cerebellar lesions (Schweizer et al., 2007). Mecklinger et al. (1999) found that patients with lesions involving the language-areas of the left hemisphere were the most affected, which could suggest the use of verbal mediation.

Functional imaging studies have shown activation of several different prefrontal regions during task-switching. Some studies have found that task-set switching involves left dorsolateral prefrontal cortex (Garavan et al., 2002; MacDonald et al., 2000; Ruge et al., 2005). However, in other studies task-switching led to activation of right-hemisphere structures, in particular the right inferior frontal gyrus (Brass et al., 2003; Dove et al., 2000; Dreher and Berman, 2002; Sohn et al., 2000). Another study (Rushworth et al., 2002) has implicated medial prefrontal structures, in particular the pre-SMA. However in this study the task-switch merely involved responses being mapped onto other stimuli without any change in either the stimulus or the response set. This differs qualitatively from more standard task-switching experiments such as those of Rogers and Monsell (1995) wherein each task requires the subject to attend to a different dimension of the same stimulus (e.g., the number as opposed to the letter in a letter-number pair such as R5). Other studies have suggested a role for more anterior prefrontal structures such as BA 10 (e.g., Braver et al., 2003; DiGirolamo et al., 2001; Dreher et al., 2002; Ruge et al., 2005).

Neuropsychological studies can be easier to interpret than functional imaging ones since they provide error patterns, and one knows that an affected region is critical for task execution (Shallice, 2003). A recent such study, that of Aron et al. (2004), is particularly important as a large number (36) of patients with well localised frontal lesions were tested. A variant of the alternating runs paradigm, developed by Rogers and Monsell (1995), was employed. On each trial a cue immediately follows the response to the preceding stimulus and the stimulus then follows after a cue-stimulus interval which could either be short $(100 \mathrm{~ms})$ or long $(1500 \mathrm{~ms})$. Rogers and Monsell (1995) had shown that a longer preparation interval reduced but did not eliminate the switch cost. Aron et al., found that the left frontal patients had larger switch costs than controls for the short cue-stimulus intervals (cf. Rogers et al., 1998). At the Long Cue-stimulus interval, however, both right and left frontal subgroups had larger switch costs than the normal controls; the patients did not use the extra preparation time as effectively as control subjects. In contrast to Mecklinger et al. (1999), Aron et al. (2004) argued that the left middle frontal gyrus was critical for taskswitching - that the role of the left frontal cortex in task-set switching is in the selection and maintenance of a task-set or schema.

A more surprising result concerned the error rates. At the short response-stimulus intervals the right frontal patients made nearly three times the errors on the switch trials compared to normal controls. On the basis of a correlation analysis between size of lesion and switch costs they localised this effect to the right inferior frontal gyrus and in particular the pars opercularis (see also Aron and Poldrack, 2006; Aron et al., 2003; Chambers et al., 2006). However, while the primary deficits for the right frontal group as a whole concerned errors, the analysis that Aron et al., used to correlate with lesion size and location involved reaction times, where for the critical short cue-stimulus intervals the right frontal group did not differ significantly from controls. Moreover, the correlations considered important in the theoretical discussion of the results involved the 'residual switch cost', that is the switch cost after the Long Cue-stimulus interval, while the critical right frontal error deficits involved both cuestimulus intervals. There was no apparent localisation derivable from the error analysis pointing to the right pars opercularis.

The findings of Aron et al. (2004) add greatly to our knowledge of the cognitive neuroscience of task-set switching. However, a number of issues need to be addressed. A major cause of the difficulties that subjects have in task-set switching is due to the co-activation of two different cognitive schemas over the course of a set of trials (Allport and Wylie, 2000). In a functional imaging experiment comparing blocks where switches can occur with single-task blocks, Braver et al. (2003) showed that tonic potentiation of two task schemas in a block leads to activation of right anterior prefrontal cortex, unlike the transient switch-related changes which were predominantly left lateral as far as the frontal cortex was concerned. The study of Aron et al. (2004), however, only included experimental blocks where both of the two tasks are potentially active. In addition, most of the anatomically critical findings relate to the measure 'switch costs', which is closely linked to one particular theory, namely that involving the task-set reconfiguration of Rogers and Monsell (1995), and it is unlikely that switch-costs transparently reflect the duration of any such process (see Gillbert and Shallice, 2002).

We therefore carried out a further study of task-set switching as part of a series of investigations of the involvement of different regions of prefrontal cortex in a variety of tasks loaded on attention-related processes. The specific experimental paradigm used cued taskswitching (cf. Meiran, 1996; Meiran et al., 2000). For each stimulus a warning signal specifies which task is relevant and this occurs either $1500 \mathrm{~ms}$ (Long Cue) or $200 \mathrm{~ms}$ (Short Cue) before the stimulus. In principle, the hypothetical process often assumed to be critical for taskswitching - namely task-set reconfiguration (Rogers and Monsell, 1995) or endogenous control (Monsell, 2003) - can take place prior to stimulus presentation in the Long Cue condition but not in the Short Cue condition. Moreover, the experimental paradigm also includes blocks where only a single task-set is relevant. These Single Task blocks provide a situation where there is no task conflict, which is important given the imaging findings of Braver et al. (2003). By contrast the Long Cue and Short Cue conditions are both situations where task conflict occurs on so-called 'incongruent' trials within a block. Such a conflict has also been shown to be neuropsychologically important in a task-switching study of patients with cerebellar lesions carried out by Schweizer et al. (2007).

\section{MATERIALS AND METHODS Subjects}

This study was an unselected case series, subject to inclusion-criteria based on baseline testing. Inclusion of different aetiologies was necessary in order to obtain patients with lesions in all frontal regions as different aetiologies have predispositions for different regions of frontal cortex (Stuss et al., 1995). The method is based on the premise that the location of lesions is more critical than the aetiology in determining cognitive deficits (Burgess and Shallice, 1996; Elsass and Hartelius, 1985; Stuss et al., 1994). Forty-one patients with focal lesions to the frontal lobes and 38 healthy control participants were participants in the study. The non-patient control group (CTL) was matched as closely as possible to the patients for age, sex, and education. All the patients were at least 2 months post acute onset (mean $=22$ months; range $=2-109$ months). The other criteria for inclusion in the series were absence of severe aphasia, no clinically detectable neglect, no significant neurological or psychiatric disorder other than that that produced the lesion and an 10 of at least 90 (Patients $m=106$; Control $m=112$ ). The aetiology of the lesions was an acquired acute disorder; these included infarction, haemorrhage (including ruptured aneurysms), trauma with no evidence of diffuse axonal injury, or resection of a benign tumour with no detectable evidence of diffuse brain pathology.

Based on our previous research, patients were assigned to one of the following four groups: left lateral frontal ( $\mathrm{LL}, n=11)$; right lateral frontal (RL, $n=6$ ); inferior medial (IM, $n=14$ ); superior medial (some subjects in this group had an extension of the lesion into the inferior medial region; see Stuss et al., 1998 for rationale; SM, $n=10$ ). Lesions in the patients in the two lateral groups could include lateral subcortical lesions involving deep frontal white matter and the dorsal caudate (see Stuss et al., 1994 for rationale). In seven patients the lesion extended to non-frontal structures. In six of these (4 RL, 2 SM) the non-frontal extension was less 
than $10 \%$ of the entire lesion (range $=3.3-8.1$, mean $=6.1 \%$ ). In one patient in the IM group, the non-frontal extension was $35 \%$.

All the lesions were localized by the use of a standard template (Stuss et al., 2002a) which was based on the methods of Damasio and Damasio (1989). Lesion size was quantified by superimposing the lesion contours for each axial slice onto a fixed pixel diagram and then counting the number of pixels within the lesion area. The percentage of total brain area damaged was obtained by dividing the lesion count by the total pixel count for all axial slices. The lesions for the patients studied are shown in Figure 1. The figure shows only 39 patients since the scans of two IM patients had been available for lesion documentation but were lost prior to quantification. The aetiology, location of lesion, time from the acute onset to that of testing, and handedness of the patients are presented in Table 1, derived from Table 2 of Alexander et al. (2005) which also includes two patients - 2195 and 2206 - that could not be tested for this study. All subjects responded with their dominant hand. None had weakness or impaired motor control. All reported normal colour vision. Measures of neglect (line bisection, and double simultaneous stimulation) were normal in the patients. The National Adult Reading Test-Revised (NART-R) was administered to provide a measure of general intellectual ability. Other neuropsychological tests measures included Digit Span forward and backward, Token Test of language comprehension, Boston Naming Test, Judgment of Line Orientation, and Beck Depression Inventory (see Table 2 for group scores). Informed consent was obtained from all participants according to the declaration of Helsinki. The experiments were approved by both the Human Subjects' Research Ethics Boards of Baycrest Centre and the University of Toronto.

\section{Procedure}

The subject was presented with a $6.7 \mathrm{~cm} \times 6.7 \mathrm{~cm}$ square window divided into four square panes (or quadrants) of internal size $3 \mathrm{~cm} \times 3 \mathrm{~cm}$. A red circle appeared in one of the four quadrants (see Figure 2). In the Upper/Lower (U/L) task the subject had to press button $1(\mathrm{~L})$ if the stimulus appeared in one of the upper quadrants and button $2(\mathrm{R})$ if it appeared in one of the lower quadrants. In the Left/Right $(L / R)$ task the subject had to press button $1(\mathrm{~L})$, if the red circle appeared in one of the left quadrants, and button $2(\mathrm{R})$ if it appeared in one of the right quadrants. The buttons

$\mathrm{LL}$
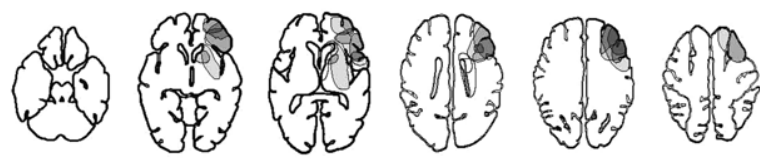

$\mathrm{RL}$
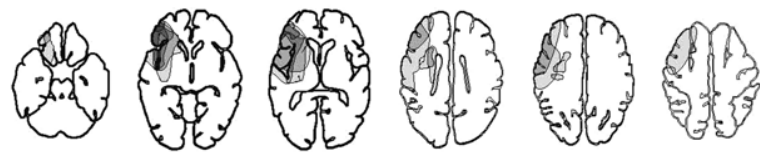

IM
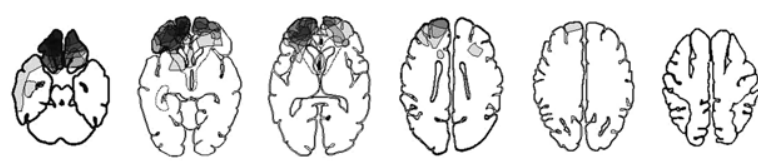

SM
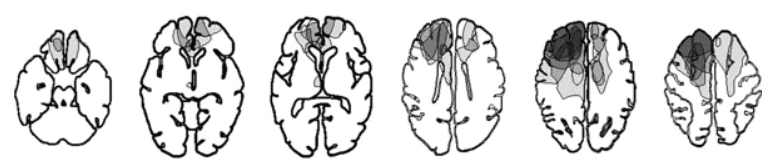

Figure 1. Lesion locations. The figure shows the lesion overlaps in the four patient groups ( $L L=$ Left Lateral (11 patients); $R L=$ Right Lateral (6 patients); $S M=$ Superior Medial (10 patients); $I M=$ Inferior Medial (14 patients)). Darker shading indicates a greater number of patients with lesions affecting the region. The scans for one patient in each of two groups (LL and IM) were unavailable for plotting. were pressed with the index finger of the dominant hand. If the stimulus appeared in the top left or bottom right positions then the same button had to be pressed whichever task was in operation; these trials were termed 'Congruent'. If the stimulus appeared in the top right or bottom left positions then the button that had to be pressed depended on which task was in operation; these trials were termed 'Incongruent' (see Figure 2).

There were three conditions, each involving separate blocks of trials. In the Single Task conditions the type of task (U/L for two blocks and L/R for two blocks), remained constant throughout the block of 26 trials. The stimuli within a block occurred in a pseudo-random order. Each stimulus was preceded by a task-cue $200 \mathrm{~ms}$ before the stimulus occurred. For the U/L task this was the words 'Upper or Lower?' appearing just below the grid in the centre of the screen; for the L/R task, the words were 'Left or Right?'. The task cue and the stimulus remained on the screen until the subject made a response. There were then two conditions in which the two types of task occurred in a pseudorandom order in the same block of 50 trials. In the Long Cue condition the task-cue occurred 1500 ms before the red circle stimulus appeared. In this condition, the participant could in theory prepare the task-set before the stimulus occurred. In the Short Cue condition, the task cue again occurred $200 \mathrm{~ms}$ before the stimulus. In this condition, the participant theoretically could not prepare the taskset before the stimulus appeared. The task-cue signal itself occurred at an interval following the previous response which was randomly selected from a rectangular distribution with limits of 1200-1800 ms (Long Cue Condition) or 2700-3300 ms (Short Cue Condition). There was a practice block of 12 trials before the first occurrence of a particular type of block. Overall there were two blocks of each of the two Single Task conditions and also of both the Long Cue and the Short Cue conditions. This allowed the effects of practice to be examined in each condition. The order of conditions was: Single U/L, Single L/R, Short Cue, Long Cue, Long Cue, Short Cue, Single L/R, Single U/L.

\section{Statistical analyses}

The measurements - mean reaction time and errors - were compared across the conditions and subject groups. Trials were excluded if the reaction time of the subject exceeded 4 standard deviations of the mean RT in that condition of the subject's group (cf. Stuss et al., 2005); in all $0.81 \%$ of trials were excluded. Two different complementary ANOVA designs were used. First, a split-plot ANOVA was used in which the performance of each of the four lesion groups is compared in turn to that of the CTL group. As this method of comparison was preplanned - indeed it is common to all the ROBBIA group of papers (e.g., Alexander et al., 2005; Stuss et al., 2005) - the standard 0.05 alpha level was used for these comparisons (see Keppel, 1982; Stuss and Alexander, 2007). This is called the Basic Groups ANOVA. If there was a significant difference for a particular group compared with controls, a second ANOVA was carried out to determine whether that patient group was significantly different from the other patients combined. This is called the Within Lesion Groups ANOVA. The aim of this two-stage analysis procedure, referred to as two complementary ANOVAs, was first to demonstrate the existence of an abnormality and then to assess whether it was specific to a particular lesion location.

In addition we performed a finer anatomical analysis (for justification see Alexander et al., 2005; Stuss et al., 2005), using the anatomical classification procedure of Petrides and Pandya (1999) (P \& P). The logic is similar to that employed in Voxel-based Lesion-Symptom Mapping (VLSM) procedures (e.g., Bates et al., 2003, Rorden and Karnath, 2004) although the anatomical grain used is much coarser. For each P \& P area in the frontal lobes, we identified all the patients who had lesions in that area. Given there were at least three such patients, their performance on a behavioural measure (e.g., number correct) was compared using a Mann-Whitney test to that of all patients who had no damage to that area. As the aim was to provide more specific anatomical location sites for an effect established behaviourally in the previous basic groups analyses, this procedure was only carried out if a significant effect of group had indeed been obtained in the basic groups analysis and Bonferroni corrections 
Table 1. Etiology, lesion location, lesion size, time since injury and handedness within patient groups.

\begin{tabular}{|c|c|c|c|c|c|}
\hline Subject & Etiology & Lesion location* & Lesion size (\%)** & TSI (months) & Handedness \\
\hline \multicolumn{6}{|c|}{ Left lateral } \\
\hline 2056 & Benign glioma resection & Dorsolateral & 0.6 & 24 & Right \\
\hline 2137 & Trauma & Ventrolateral & 1.3 & 95 & Right \\
\hline 2149 & Trauma & Dorsolateral & 0.2 & 7 & Right \\
\hline 2152 & Trauma & Dorsolateral & 0.2 & 8 & Right \\
\hline 2156 & Hemorrhage & Caudate & 1.1 & 6 & Right \\
\hline 2174 & Hemorrhage & Dorsolateral, ventrolateral & 2.0 & 24 & Right \\
\hline 2177 & Meningioma resection & Dorsolateral, ventrolateral & 3.3 & 7 & Right \\
\hline 2191 & Infarction & Caudate & 0.8 & 24 & Right \\
\hline 2197 & Trauma & Dorsolateral, ventrolateral & 1.3 & 2 & Right \\
\hline 2208 & Meningioma resection & Dorsolateral & 0.4 & 14 & Right \\
\hline \multirow[t]{2}{*}{2210} & Meningioma resection & Dorsolateral, ventrolateral & 0.8 & 22 & Right \\
\hline & & & 1.1 & 21 & \\
\hline \multicolumn{6}{|c|}{ Right lateral } \\
\hline 2154 & Infarction & Ventrolateral & 0.1 & 15 & Right \\
\hline 2161 & Meningioma resection & Ventrolateral & 0.4 & 6 & Right \\
\hline 2181 & Meningioma resection & Ventrolateral, corpus callosum, caudate & 2.5 & 6 & Right \\
\hline 2186 & Meningioma resection & Dorsolateral & 2.7 & 5 & Right \\
\hline 2188 & Infarction & Ventrolateral, corpus callosum, caudate & 2.6 & 19 & Right \\
\hline \multirow[t]{2}{*}{2202} & Infarction & Dorsolateral, ventrolateral & 3.9 & 30 & Right \\
\hline & & & 2.0 & 13 & \\
\hline \multicolumn{6}{|c|}{ Inferior medial } \\
\hline 2047 & Hemorrhage/SAH & Inferior medial (R) & 0.4 & 4 & Right \\
\hline 2053 & Trauma & $\begin{array}{l}\text { Polar }(\mathrm{R}) \text {, Inferior medial }(\mathrm{R}) \text {, } \\
\text { dorsolateral }(\mathrm{L}), \mathrm{ACG}(\mathrm{R})\end{array}$ & 2.4 & 25 & Right \\
\hline 2134 & Trauma & Polar (L \& R), inferior medial ( $L$ \& R) & 3.9 & 91 & Right \\
\hline 2140 & Infarction/SAH & Inferior medial (L \& R), ACG (L) & 1.2 & 48 & Right \\
\hline 2142 & Trauma & $\begin{array}{l}\text { Polar }(L \& R) \text {, ventolateral }(R) \text {, } \\
\text { dorsolateral }(R) \text {, inferior medial }(L \& R)\end{array}$ & 3.2 & 21 & Right \\
\hline 2143 & Trauma & $\begin{array}{l}\text { Polar }(L \& R) \text {, inferior medial }(L \& R) \text {, } \\
\text { ventrolateral }(R)\end{array}$ & 3.7 & 27 & Ambi \\
\hline 2146 & Trauma & $\begin{array}{l}\text { Polar }(L \& R) \text {, inferior medial }(L \& R) \text {, } \\
\text { ventrolateral }(R) \text {, corpus callosum }(L \& R) \text {, } \\
\text { caudate }(R)\end{array}$ & 4.6 & 48 & Right \\
\hline 2148 & Trauma & Polar (L \& R), inferior medial (L \& R) & 3.3 & 11 & Ambi \\
\hline 2166 & Meningioma resection & Polar (R), inferior medial (L \& R) & 0.6 & 6 & Right \\
\hline 2169 & Hemorrhage/SAH & Polar (L) & $* * *$ & 109 & Right \\
\hline 2180 & Infarction/SAH & Polar (R), inferior medial (R) & $* * *$ & 28 & Right \\
\hline 2196 & Trauma & $\begin{array}{l}\text { Polar }(R) \text {, dorsolateral }(R) \text {, } \\
\text { inferior medial }(L \& R)\end{array}$ & 2.4 & 14 & Right \\
\hline 2198 & Hemorrhage & Inferior medial (L \& R) & 0.3 & 10 & Right \\
\hline \multirow[t]{2}{*}{2203} & Trauma & Inferior medial (R) & 1.0 & 12 & Left \\
\hline & & & 2.3 & 32 & \\
\hline \multicolumn{6}{|c|}{ Superior medial } \\
\hline 2131 & Trauma & Polar (L), superior medial (L) & 1.7 & 52 & Ambi \\
\hline 2135 & Trauma & Superior medial (R) & 0.6 & 6 & Right \\
\hline 2151 & Infarction & $\begin{array}{l}\text { Corpus callosum }(L \& R) \text {, polar }(R) \text {, } \\
\text { inferior medial }(R) \text {, superior medial }(R) \text {, } \\
\text { dorsolateral }(R) \text {, ventral lateral }(R)\end{array}$ & 4.1 & 37 & Right \\
\hline 2153 & Trauma & $\begin{array}{l}\text { Ventrolateral }(R) \text {, superior medial }(R) \text {, } \\
\text { dorsolateral }(R)\end{array}$ & 7.0 & 37 & Right \\
\hline 2159 & Hemorrhage & $\begin{array}{l}\text { Corpus callosum }(\mathrm{L} \& \mathrm{R}) \\
\text { superior medial }(\mathrm{R}) \text {, dorsolateral }(\mathrm{R})\end{array}$ & 4.2 & 31 & Right \\
\hline 2185 & Infarction & $\begin{array}{l}\text { Polar }(R) \text {, inferior medial }(R) \text {, } \\
\text { ventrolateral }(R) \text {, corpus collosum }(R) \text {, } \\
\text { superior medial }(R)\end{array}$ & 11.0 & 6 & Right \\
\hline 2190 & Meningioma resection & $\begin{array}{l}\text { Corpus callosum }(R) \text {, polar }(R \& L) \text {, } \\
\text { inferior medial }(L) \text {, superior medial }(R \& L) \text {, } \\
\text { dorsolateral }(R \& L)\end{array}$ & 11.5 & 9 & Ambi \\
\hline
\end{tabular}


Table 1. Continued

\begin{tabular}{lllccc}
\hline Subject & Etiology & Lesion location* & Lesion size (\%)** & TSI (months) & Handedness \\
\hline 2194 & Infarction/SAH & Polar (L \& R), inferior medial (L \& R), & 3.2 & 20 & Right \\
& & Superior medial (L \& R) & & & \\
2199 & Hemorrhage & Dorsolateral (R), superior medial (R) & 2.1 & 28 & Ambi \\
2209 & Meningioma resection & Corpus callosum (R), superior medial (R) & 1.8 & 10 & Right \\
& & & $\mathbf{4 . 7}$ & $\mathbf{2 3}$ & $\mathbf{1 2 2 . 6}$
\end{tabular}

SAH: intracerbral lesion due to ruptured aneurysm.

* Only areas of maximum pathology are identified.

** Percent of whole brain.

***Scan lost after initial classification.

Table 2. Subject demographic and neuropsychological test data.

\begin{tabular}{llllll}
\hline & CTL & LL & RL & IM & SM \\
\hline Number (female/total) & $22 / 38$ & $3 / 11$ & $2 / 6$ & $5 / 14$ & $5 / 10$ \\
Age (years) & $49 \pm 16$ & $43 \pm 12$ & $47 \pm 13$ & $46 \pm 16$ & $48 \pm 15$ \\
Education (years) & $15 \pm 2$ & $13 \pm 2 *$ & $16 \pm 2$ & $14 \pm 2$ & $13.5 \pm 2 *$ \\
NART-R & $112 \pm 7$ & $104 \pm 9 *$ & $113 \pm 10$ & $107 \pm 8$ & $104 \pm 12$ \\
Digit span & $7.1 \pm 1.5$ & $6.3 \pm 0.9$ & $6.3 \pm 1.4$ & $6.4 \pm 1.3$ & $6.7 \pm 1.6$ \\
Boston naming test & $55 \pm 4$ & $53 \pm 4$ & $57 \pm 3$ & $53 \pm 9$ & $52 \pm 4$ \\
Beck depression inventory & $6.1 \pm 5.9$ & $9.1 \pm 7.9$ & $11.3 \pm 11.7$ & $8.63 \pm 9.3$ & $8.4 \pm 9.7$ \\
Lesion size (\% brain) & & $1.1 \pm 0.9$ & $2.0 \pm 1.5$ & $2.3 \pm 1.5$ & $4.7 \pm 3.9$ \\
Time since injury (month) & & $21 \pm 26$ & $13 \pm 10$ & $32 \pm 32$ & $23 \pm 16$ \\
\hline
\end{tabular}

Means \pm standard deviations for all data except the numbers of subjects. NART-R is National Adult Reading Test Revised. Significant Asterisks show differences from CTL.

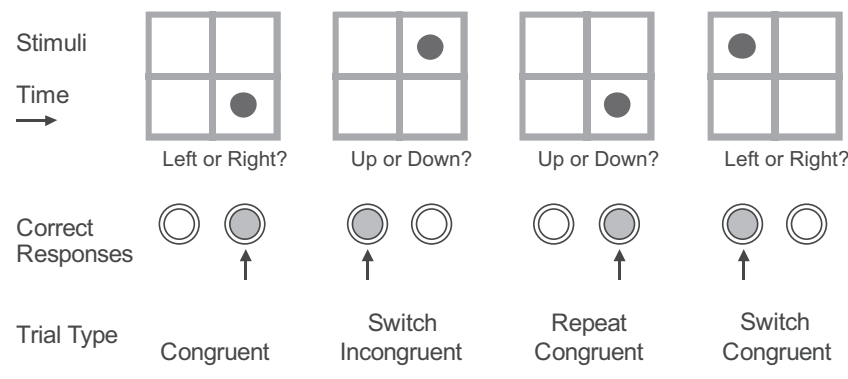

Figure 2. Stimulus paradigm. Correct responses and trial-types for three successive trials of one of the two cued conditions.

were not used. We considered all areas with a one-tailed $p<0.1$ as potentially involved in the processes that determined the measurement, and areas with a one-tailed $p<0.05$ as definitely involved.

\section{RESULTS}

\section{Reaction times}

Single task condition. The most basic condition is the Single Task one, in which each task is presented independently for a complete block of trials. Two complementary ANOVAs with factors Task (U/L $v \mathrm{~L} / \mathrm{R})$ and Group were carried out. Overall in the Basic Groups ANOVA, the horizontal decision was faster than the vertical one $(F(1,74)=15.0, p<0.001)$. Only the SM group was slower than both the CTL group $(F(1,74)=7.30$, $p=0.009$ ) (in the Basic Groups ANOVA) and the Other Patient groups $(F(1,39)=8.04, p=0.007$ ) (in the Within Lesion Groups ANOVA) (see Figure 3). There was no significant difference between performance on the first and second blocks in either single task condition.
Switch task conditions. Two complementary 4-way ANOVAs were carried out which involved Patient Group as a between-subject factor and as withinsubject factors Cue Type (Long, Short), Trial Type (Repeat, Switch) and Block (First, Second). The first of these was a split-plot ANOVA comparing the four patient groups with the controls; it was followed by a secondary ANOVA comparing any critical patient group with the other patient groups combined. Again only one patient group behaved differently from the other patient groups and the controls - the SM group (Basic Groups ANOVA - SM v CTLs: $F(1,74)=24.17, p<0.001$; Within Lesion Groups ANOVA - SM v Other Patient Groups: $F(1,39)=19.16 ; p<0.001$ ) (see Figure 4). This group was far slower than any other - $948 \mathrm{~ms}$ slower than the CTL group in the Long Cue condition and $1250 \mathrm{~ms}$ slower in the Short Cue condition. The effect of Cue Type was significant (Basic Groups ANOVA $-F(1,74)=34.33, p<0.001$ ); with subjects being faster in the Long Cue condition than in the Short Cue one. The SM group showed an increased slowing in the Short Cue condition compared to both the Controls (Basic Groups ANOVA $-F(1,74)=15.24$, $p<0.001$ ) and the Other Patient Groups (Within Lesion Groups ANOVA $-F(1,39)=9.33, p<0.005)$. The effect of Block was not significant for any patient group, and no interaction involving this factor was significant. There was, however, an overall effect of Trial Type with Switch trials being slower than Repeat ones (Basic Groups ANOVA - $F(1,74)=13.04, p<0.002$ ). In addition there was a significant interaction between Group and Trial Type; again the SM group behaved differently showing a greater switch cost compared to the Controls (Basic Groups ANOVA $-F(1,74)=21.38, p<0.001$ ) and to Other Patient Groups (Within Lesion Groups ANOVA $-F(1,39)=16.17$, $p<0.001)$. Thus for the Long Cue condition, the switch cost in the SM group was $433 \mathrm{~ms}$ by comparison with $128 \mathrm{~ms}$ in the CTL Group and from 59 to $113 \mathrm{~ms}$ in the other Patient Groups. In the Short Cue condition the switch cost for the SM group was $412 \mathrm{~ms}$ compared to that of $115 \mathrm{~ms}$ for the CTLs and $35-150 \mathrm{~ms}$ for the other patient groups. The other patient groups, including the LL one, showed no sign of an abnormally large switch cost. 


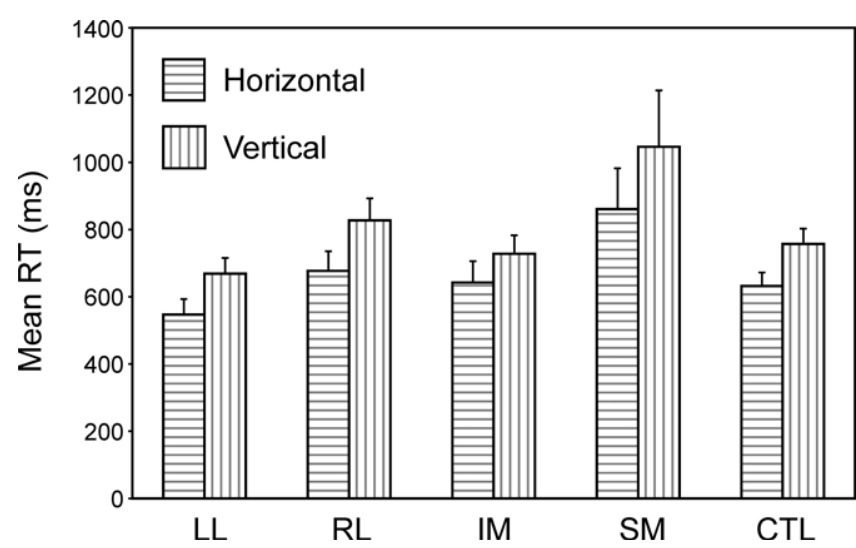

Figure 3. Single task conditions. Mean reaction times and standard errors for the four patient groups and the controls on the two tasks (horizontal and vertical).

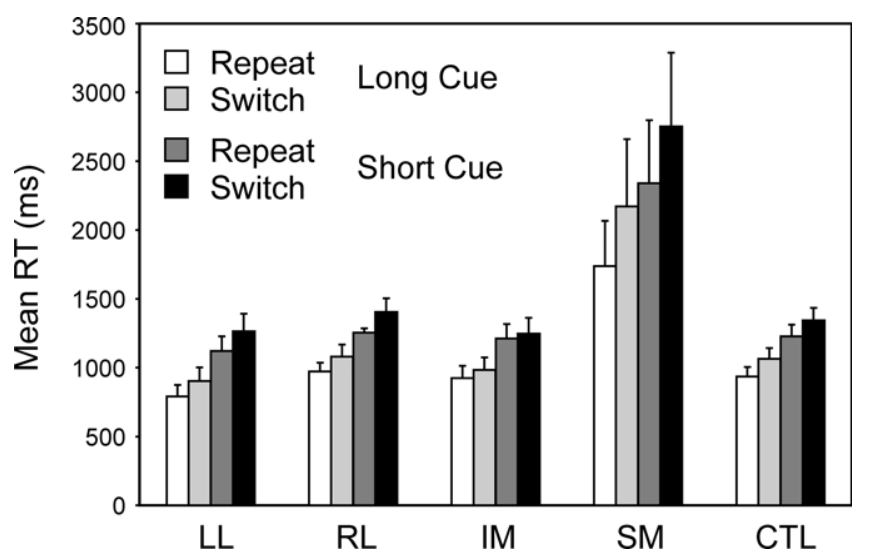

Figure 4. Switch vs. Repeat. Mean reaction times and standard errors for the four patient groups and the controls on Repeat and Switch trials in the Long Cue and Short Cue task conditions.

In a subsidiary analysis, the effect of the congruency of the stimulusresponse mapping was examined (see Figure 5). Two complementary 4-way ANOVAs were carried out with three within-subject factors Cue Type (Long, Short), Trial Type (Switch, Repeat) and Congruency and one between-subject factor, Group. There was a significant effect of congruency (Basic Groups ANOVA - $F(1,74)=7.10, p, 0.01$ ), with the incongruent stimulus eliciting the longer RT. There was also a strong trend for an interaction with congruency for the SM group by comparison both with respect to the CTLS (Basic Groups ANOVA - $F(1,74)=3.56$, $p=0.06$ ) and with respect to the Other Patient Groups (Within Lesion Groups ANOVA $-F(1,39)=3.81, p=0.06)$. The responding of the SM group appeared to be slowed more than that of the other groups by having incongruent rather than congruent stimuli.

Specific tasks. Two complementary 4-way ANOVAs were carried out to investigate the effect of the specific task, and in particular whether the decision involved the vertical or horizontal dimension of stimulus position (Task Direction), the other three factors being Group, Trial Type (Switch, Repeat) and Condition (Short Cue, Long Cue). As well as the effects of group and trial type expected from the preceding ANOVAs, there was a significant effect of Task Direction, vertical being harder than horizontal (Basic Groups ANOVA $-F(1,74)=10.412, p=0.002$ ) (see Figure 6). More critically, there was a significant interaction involving Task Direction and group

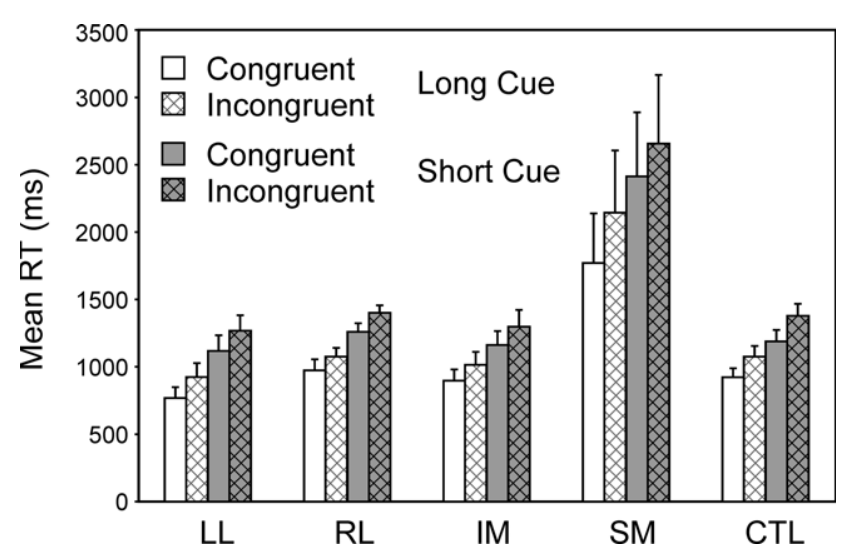

Figure 5. Effects of congruency. Mean reaction times and standard errors for the four patient groups and the controls on Congruent and Incongruent trials in the Long Cue and Short Cue task conditions.

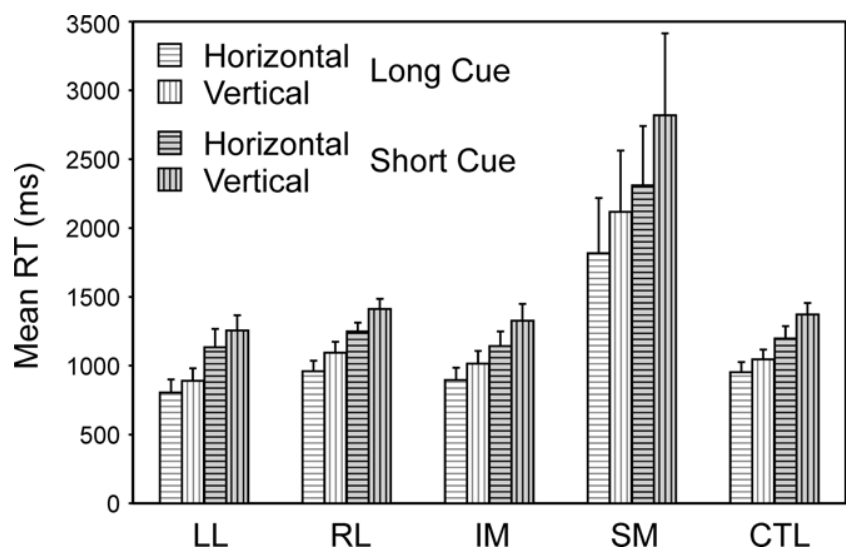

Figure 6. Horizontal vs. vertical. Mean reaction times and standard errors for the four patient groups and the controls on Horizontal and Vertical trials in the Long Cue and Short Cue task conditions.

where the SM group was concerned (Basic Groups ANOVA - SM v CTLs: $F(1,74)=11.05, p<0.002$; Within Lesion Groups ANOVA - SM v Other Patient Groups: $F(1,39)=6.12, p<0.02$ ). The SM group slowed more when faced with the more difficult vertical task.

Ratio of switch cost to base reaction time. Given that the SM group shows a much greater switch cost but is also much slower overall, the issue arises as to whether its switch cost was disproportionately greater than would be expected given the overall slower reaction time. Two complementary 2-way ANOVAs comparing Cue type (Long, Short) and Group were carried out on the measure switch cost/mean RT for the condition (ratio switch cost RT). With this ratio measure there was no longer a significant effect for the SM group (Basic Groups ANOVA $-F(1,74)=1.89$, $p=0.17)$. There was however a significant effect for the IM group which had a significantly smaller ratio switch cost RT than both the controls (Basic Groups ANOVA $-F(1,74)=4.52, p<0.05$ ) and the 0ther Lesion groups (Within Lesion Groups ANOVA $-F(1,39)=8.45, p<0.01$ ).

'Mixed list cost': the cost of having two tasks active. If one contrasts performance in the single task conditions with that in the repeat trials of the switch task conditions then one has a measure which relates to the cost of having two tasks active rather than one (see Meiran et al., 2000). When the patient groups are compared with the controls on this measure 


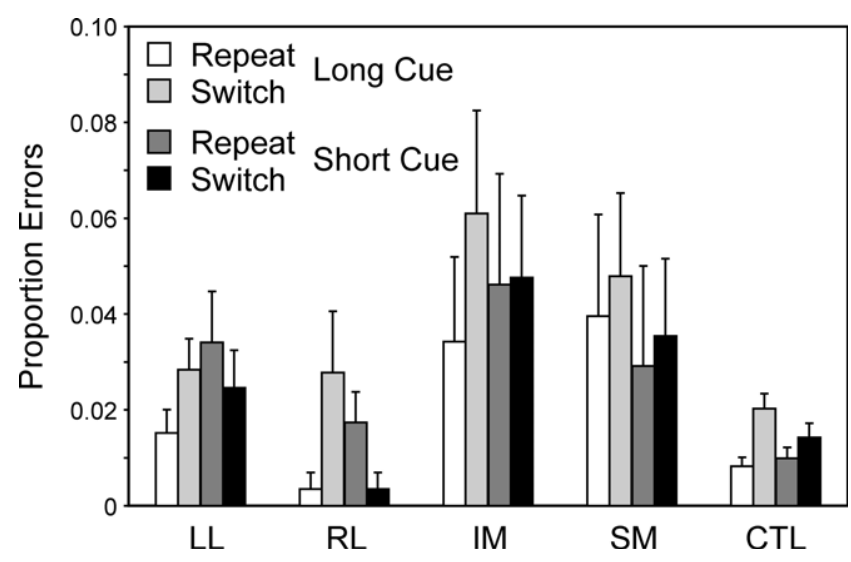

Figure 7. Error rates. Mean error rates (with standard errors of the mean) of the four patient groups and the controls on Repeat and Switch trials in the Long Cue and Short Cue task conditions.

there is still a strong and significant deficit in the SM group (Basic Groups ANOVA $-F(1,74)=27.12, p<0.001)$.

\section{Errors}

Single task conditions. There were no significant differences across groups or tasks in the error rates, which were minimal.

Switch task conditions. In all groups virtually all the errors occur on incongruent trials. As for the reaction times two complementary 4-way ANOVAs were carried out with factors Cue Type (Long, Short), Trial Type (Switch, Repeat), Block (1 $\left.1^{\text {st }}, 2^{\text {nd }}\right)$ and Group. Overall there was an effect of Trial Type (Basic Groups ANOVA $-F(1,74)=6.28$; $p=0.014$ ) with more errors on switch trials, but no interaction of this factor with patient group. There was no effect of Block or interactions with this factor. The IM group made significantly more errors than the CTL group (Basic Groups ANOVA $-F(1,74)=8.39, p<0.01)$. Thus in the Long Cue condition IM groups made over five times the number of errors as the CTL group and in the Short Cue condition over three times as many (see Figure 7). The IM group, however, did not produce significantly more errors than the Other Patient groups combined in the Within Lesion Groups ANOVA, in part because the SM group showed a strong trend to produce more errors than the CTL group (Basic Groups ANOVA $-F(1,74)=3.45, p=0.07$ ).

Surprisingly there were no significant effects of Cue Type or Trial Type. However, there was a second effect which concerned the LL group. There were significant interactions between Block (first and second) and patient group (Basic Groups ANOVA - LL v CTLs: $F(1,74)=5.02, p<0.05$ ). The interaction arises from the $\mathrm{LL}$ group producing significantly more errors on the first Task Block of a cue type than on the second such Block (see Figure 8). The effect is particularly pronounced on the Short Cue Task, where the effect was significant at the 0.01 level; it should be noted that the two Short Cue Task Blocks are separated by two intervening blocks involving the Long Cue Task condition. The improvement occurring in the LL group can be seen by the way in which on the first Short Cue Task block, the LL group had a virtually identical error rate to the IM group, but on the second such block, IM patients had about four times as high an error rate as the LL group.

In a subsidiary analysis the error switch cost was compared across the two Long and Short Cue conditions; there was a significantly greater switch cost in the Long Cue than in the Short Cue condition when all subjects were considered [Wilcoxon $n=58, t=474, p<0.005$ (2 tail)], when patients alone were considered [Wilcoxon $n=30, t=105.5$, $p<0.01$ (2 tail)] but not when controls alone were considered (Wilcoxon $n=28 ; t=137, p>0.1)$.

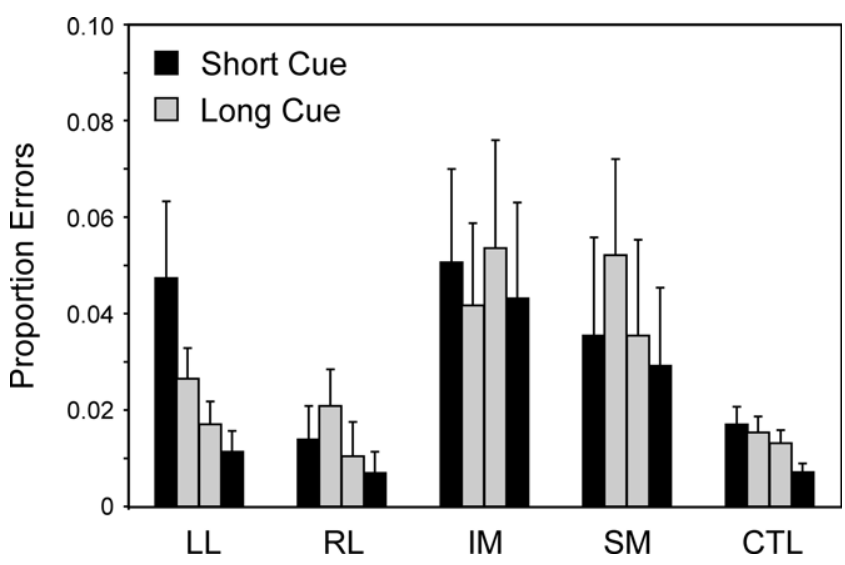

Figure 8. Errors over time. Mean error rates (with standard errors of the mean) of the four patient groups and the controls on the first and second blocks of the Long Cue and Short Cue task conditions. The results are plotted from left to right in the order that the blocks occurred during the sessionShort Cue, Long Cue, Long Cue, Short Cue.

More detailed anatomy: the errors induced by having two tasks active. The effect on RT of SM lesions was similar to effects found in other studies (see Stuss and Alexander, 2007; Stuss et al., 2005). This was not the case for the error patterns, where increased error rates were found in the IM group with only a trend in the SM groups on the Basic Groups ANOVA. On the more detailed analysis of the combined errors induced by having two tasks active, patients with lesions in left areas $9 \mathrm{~m}, 110,14 \mathrm{~m}$ and $47 / 120$ made more errors at the 0.05 level than patients whose lesions did not involve this area and with patients with lesions in left areas 10i, 100, 140, 47/120 and right area 47/12v making significantly more errors at the 0.1 level than patients whose lesions did not involve the respective specific areas. (see Figure 9). No other detailed analysis of error patterns produced significant effects at the 0.05 level.

In the basic group analysis, there was a significant decrease in the number of errors that occurred between the first and second blocks of each condition. For the anatomically more detailed analysis, the measure used was of:

\section{$1^{\text {st }}$ Block Errors $-2^{\text {nd }}$ Block Errors}

for the Long Cue and Short Cue Task conditions combined. For each region whether there was a significant difference between the patients producing high and low scores on this measure was assessed. Regions left $9 / 46 \mathrm{v}$ and right $6 \mathrm{~A}$ gave significant effects at the 0.1 level. If one restricts consideration to the Short Cue condition alone, which corresponds to assessing the difference between the first and last blocks of the set of four switching conditions, then a significant difference at the 0.05 level in favour of high scores was found in the left dorsolateral region $(9 / 46 v)$ only.

\section{DISCUSSION}

Nearly all previous studies of task-switching carried out with frontal lobe patients have involved small patient samples so it is not possible to draw strong conclusions about the localisation of any relevant processes within the frontal cortex. The major exception is the study of Aron et al. (2004) in which 36 patients with lesions to frontal cortex were assessed. In the Aron et al., study, a variant of the so-called 'alternating runs' procedure developed by Rogers and Monsell (1995) was used in which the specific task that is relevant on each trial can be predicted in advance. The current investigation with 41 patients is the second study with a sufficiently 

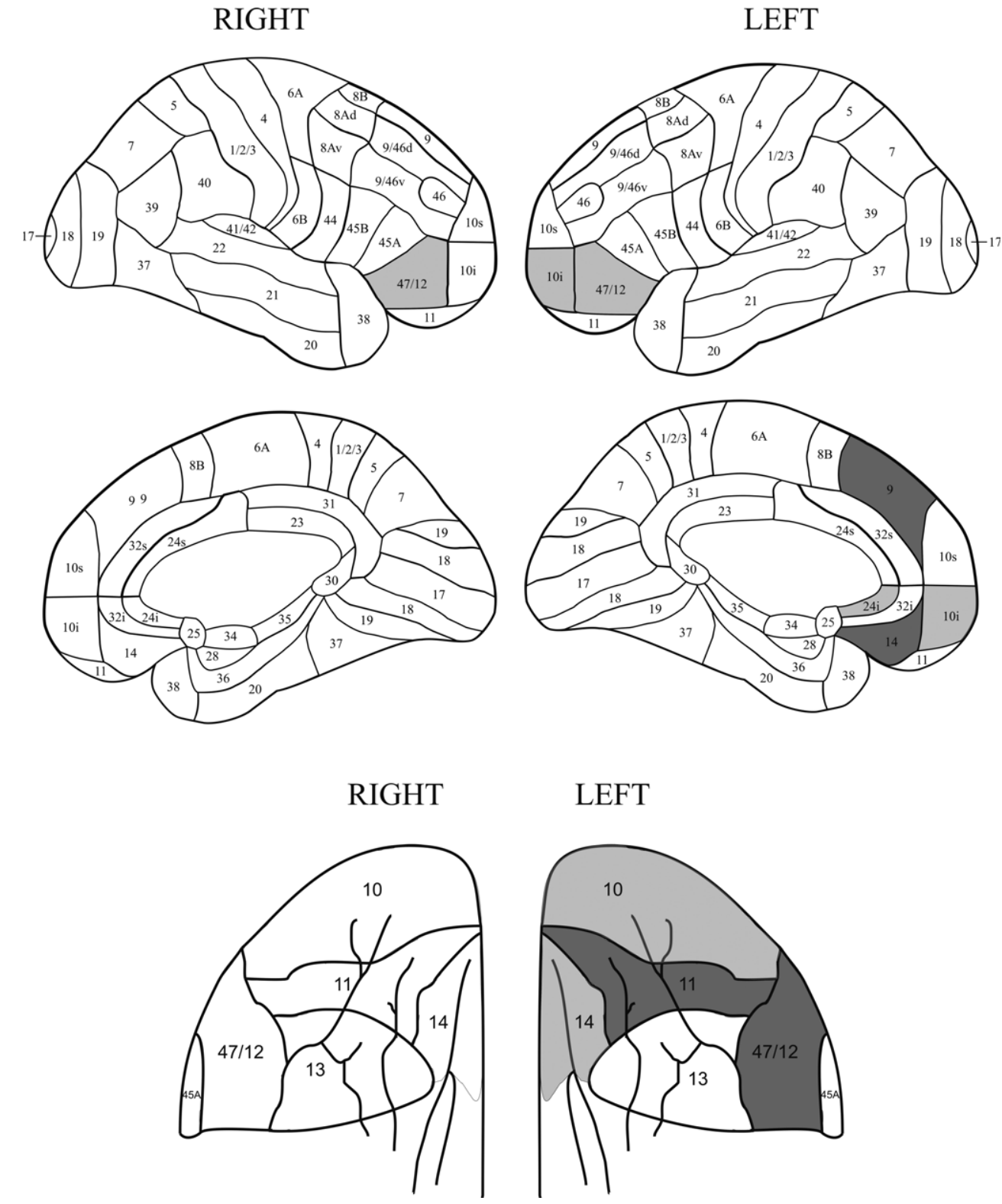

LEFT

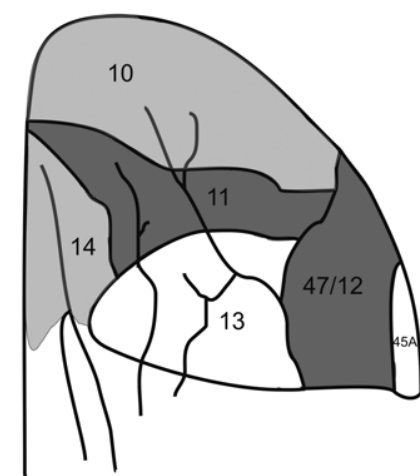

Figure 9. Relation of errors to lesions. Location of lesions with respect to the increased rate of errors in the Long Cue and Short Cue conditions combined. The figure shows regions where the error switch cost is largest. The dark grey shading indicates a region where the effect is significant at the 0.05 level or better, with the light grey representing the 0.1 level. The diagrams of the orbital regions are placed so as to facilitate comparisons with the corresponding diagrams of the lateral and medial surfaces.

large patient sample to investigate localisation of processes within frontal cortex. However, a paradigm relating to one developed by Meiran (1996) was employed in which the only information the subject has as to which task is relevant on a given trial comes from the immediately preceding cue. Three different regions of prefrontal cortex produce impairments with respect to at least one aspect of task-switching. What is most striking is the difference in the pattern of results compared with those of the Aron et al., study. The contrast in results serves to underline the complexity of the processes underlying task-switching and the sensitivity of the results to specific aspects of the experimental paradigm. It also points to the possible importance of methods of grouping neuropsychological patients.

In the current study three of the four frontal groups - LL, RL and IM - were virtually identical to the CTL group on basic RT and on switch costs in all conditions. By contrast, there was a large and significant slowing of basic RT in the SM group. The SM group was roughly $50 \%$ slower than the CTL group in the Single Task condition - a difference of $252 \mathrm{~ms}$. However it had an overall RT roughly double the basic RT of the CTLS in both the Long Cue and Short Cue conditions, with a slowing of 948 and $1250 \mathrm{~ms}$, respectively. Moreover the switch cost was $433 \mathrm{~ms}$ and $412 \mathrm{~ms}$ in the Long and Short Cue conditions, respectively, compared to 128 and $115 \mathrm{~ms}$ in the CTL group. In the Aron et al., study, there were only marginal differences from the current study in the length of their Short and Long Cue intervals. Yet switch cost was principally increased in the Left Frontal group together with the Right Frontal group in the Long Cue condition. Turning to errors, the current study gave abnormal effects in the IM, the SM and the LL groups while the Aron et al., study found a Right Frontal effect.

Why might these differences exist? One possibility is that the current grouping procedure, which used four frontal groups and did not restrict patient selection to those with unilateral lesions, might give more specific basic group localisations than the Aron et al., study which 
initially just differentiated between Left and Right Frontal groups and used only unilateral lesion patients. This might provide a partial explanation, as the critical SM group which provided such strong RT and switch-cost effects in the current study, involved 2 unilateral left, 6 unilateral right and 3 bilateral patients and would not have shown up as a distinct group in the Aron study. However, to use this as an argument for equivalence across studies would be weak, as in the Aron et al., study, the medial part of the lesions were much smaller than the lateral parts in the Left Frontal group; this makes it implausible to attribute the impairments of the LL group in the Aron et al., study to the medial part of the lesions. So taking a localisation-of-function perspective, the effects found with this group in the current study seem unlikely to derive from the same process as that producing the strongly significant Left Frontal effect on switch costs found by Aron et al., in their Short Cue condition.

A more likely source of the difference in pattern between the two sets of results lies in a key behavioural difference between the way the two paradigms are carried out. In the study of Aron et al., there was a considerable reduction in switch costs in their Long Cue condition $(1500 \mathrm{~ms}$ between cue and stimulus) compared with their Short Cue (100 ms) condition. In the current study the preparation which the Long Cue condition allows leads to a large reduction in reaction time for all groups, compared with how they perform in the Short Cue condition. This decrease is $287 \mathrm{~ms}$ for the CTL group and $613 \mathrm{~ms}$ for the SM group. However, there was no substantial change in the switch cost between the Long Cue and Short Cue conditions for any of the groups. Yet participants have $1500 \mathrm{~ms}$ to prepare the appropriate task-set in the Long Cue condition, but only $200 \mathrm{~ms}$ in the Short Cue one.

The reduction of switch costs with an increased cue-stimulus interval found in the Aron et al., study is the more typical finding in the literature (see e.g., Monsell, 2003). However, no reduction in switch cost with increased preparation time has also been found in a number of other studies (e.g., Altmann, 2004; Dreisbach et al., 2002; Sohn and Carlson, 1998). Indeed, Meiran and Gotler (2001) have argued that older subjects, who are well represented in the current study, when compared to younger ones who are the typical participants in most task switching studies, show much bigger switch costs and residual costs (Long Cue vs. Single Task condition) but preparation costs (Short Cue vs. Long Cue) are not increased. Thus preparation effects would, relatively speaking, be smaller in subjects such as those in our sample.

This lack of an effect on switch costs of the length of time subjects have to prepare is unlikely to be because subjects just ignore the verbal task specification (e.g., Left or Right?) in the $1500 \mathrm{~ms}$ of the Long Cue interval. A correct Repeat response in that condition for most groups is taking little more than 200 ms longer than in the Single Task condition, so to process and organise a response to the cue in that time instead of also using the preceding $1500 \mathrm{~ms}$ seems most implausible. Moreover, in another task-switching paradigm, Monsell and Mizon (2006) found word cues more effective than picture cues. Also it seems unlikely that subjects are still in the process of acquiring the appropriate procedure to interpret the cue indicating the task-set (see Logan and Bundesen, 2003; Monsell, 2003). In the present study the main effect of Block, and its interactions with lesion group were all far from significant as far as reaction time was concerned, which does not suggest that the subjects in most groups were changing strategy over the course of the experiment. Instead a possible factor in the present paradigm is that we roughly equalised the rate of responding in the two conditions by having different response-to-cue intervals (Short Cue $3000 \mathrm{~ms}$, Long Cue $1500 \mathrm{~ms}$ ). A response-to-cue interval of 3 second has been found to reduce switch costs, possibly by allowing task set to dissipate (Meiran et al., 2000, but see Altmann, 2005). Another way to explain the pattern is to use an approach associated with De Jong (2000), in terms of the subjects in our study, by comparison with typical young student subjects, being less willing to actively use the preparation interval to attend to a specific dimension. Indeed blocked presentation, as used in our study, might have encouraged subjects to prepare when to respond rather than how to respond (see Altmann, 2005; Meiran et al., 2000 for related discussions).

Support for this hypothesis can be found in the nature of the errors. In the Short Cue condition they occur almost equally on Switch and Repeat trials; subjects do not show a switch cost in errors; on the Long Cue condition, however, there are roughly double the number on Switch than Repeat trials. The difference in the error switch-cost between the Short and Long Cue conditions is highly significant and opposite to that to be expected if task-set reconfiguration is occurring during the preparation interval. By contrast the control group in Aron et al.'s study show the more typical reductions in the switch cost both for reaction time and errors in going from the Short to Long cue interval. There would therefore appear to be considerable differences in the strategies used by the subjects in the two studies. Direct comparisons of the localisation of particular behavioural effects between the two studies are therefore probably not useful.

It would appear that in this particular version of switch task the process of selecting a different task-set tends to occur only when the stimulus arrives, even in the Long Cue condition. The cue may instead act as a general warning signal speeding up processes other than the selection of the task-set and particularly facilitating responding on the repeat trials. So the error rate falls on repeat trials relative to switch ones. On this perspective how should one interpret the effects found in lesion groups? We will consider the SM, IM and LL groups in turn.

\section{The superior medial group}

There was a highly selective slowing in the SM group across both conditions and an increase in errors which was significant in the Long Cue condition. The increase in RT reproduced effects found in a number of previous studies of RT paradigms (Alexander et al., 2005; Stuss and Alexander, 2007; Stuss et al., 2002b, 2005). It needs further investigation to determine whether the disproportionate increase in the theoretically critical switch cost measure found in the SM group has the same cause as the selective slowing seen in earlier simpler reaction time studies. The possibility that the cause is the same, arises because for RTs, switch cost is significantly lengthened only in the SM group and not in any other frontal group. Moreover, the magnitude of the slowing of reaction time in the SM group by comparison with, say, the CTL group was also affected by other variables. For instance, it was greater if the decision required the generally harder (vertical) - than the generally easier (horizontal) - dimension. Presumably, the vertical decision was harder, because in the horizontal case the mapping of response to stimulus (such as left stimulus requiring a left response) is highly compatible and in the vertical decision this mapping would have to be inhibited. A similar effect was found for incongruency; incongruency cost was greater for the SM group at least by comparison with the CTL group. This group slowed significantly more than the others in moving from the Long Cue to the Short Cue condition. Most critically, when an analysis was carried out across groups on the measure of the ratio of Switch Cost/Mean RT, this was little higher in the SM group than in other groups, with the effect being far from significant.

These findings could be related to phenomena observed in an earlier reaction time study (Stuss et al., 2005). In that study when a warning signal occurs a fixed length of time before a stimulus for a block of trials, reaction times are slower if the foreperiod lasts 3 seconds rather than 1 second; this slowing with longer foreperiods, just like the basic reaction time, is significantly greater in the SM group than in the other frontal patients or the CTLS. Turning to errors, those the group make appear to reflect a related process; the three subjects in the group who made most errors in the experiment $-37,14$ and 6 , respectively - were the slowest patients of all with average RTs of $4.5,4.6$ and 2.7 seconds, respectively.

The greater switch cost in the SM group may therefore arise from some impairment or impairments that affect many other situations involving RT measures. Given the localisation it could result from an impairment in 'energising', the processes held to be required 
whenever the computation of which response should be produced is not solely a result of standard triggering of well-learned schemata in contention scheduling on the Norman-Shallice model (Stuss and Alexander, 2007; Stuss et al., 1995, 2005). One possibility is that any type of difficulty encountered by an organism leads to top-down activation of a system located in the SM region which in turn leads to an energising of task-relevant cortical processes, possibly by means of a circuit involving anterior cingulate $\geq$ locus coeruleus $\geq$ noradrenergic system (Mottaghy et al., 2006; Sturm et al., 1999) Thus, on an interactive activation model of task-switching, such as that of Gilbert and Shallice (2002), the amount by which the activation levels of action schema units are increased as a result of a given input to a unit would be reduced. In this case the lengthening of the switch cost in the SM group would not imply that switching is directly mediated by the region; one could not for instance infer that endogenous control (or task-set reconfiguration) is a process carried out in the SM region. This conclusion fits with the perspective derived from certain neuroimaging studies where the same frontal network was found to be involved on both switch and repeat trials (e.g., Brass and von Cramon 2004; Dove et al., 2000; Ruge et al., 2005; and in older subjects DiGirolamo et al., 2001).

There is a second type of conclusion that one can draw from these lines of argument. Any finding of an increase of RT switch cost in a frontal group which contains patients with medial frontal lesions, and where no consideration is made of whether any lengthening of basic RT has occurred, would be easy to misinterpret. It may merely reflect an unspecific effect of the greater difficulty of the switch condition.

An alternative explanation of the SM group's greater switch costs which cannot be ruled out is that they arise from damage to specific regions within the superior medial region that have a more special role in task-switching. One such possibility derives from the way that task switching paradigms entail the activation of two conflicting task-sets during a block of trials. Thus two task-sets are primed and conflicting responses will in turn be activated. SM structures, more specifically the anterior cingulate, have been extensively discussed in the context of the monitoring of response conflict (e.g., Botvinick et al., 1999; Carter et al., 1998). Loss of these monitoring functions might be expected to lead both to a particular slowing in the switch condition compared to single task conditions, and this is indeed found, and also to an increase in errors, and there is a near-significant trend for such an increase. A second possibility derives from Walton et al.'s (2004) suggestion that certain regions of the superior medial region, in particular the pre-SMA, may play a specific role in a process related to task-switching, In particular they held it to relate to voluntary selection between response sets, where this corresponds to the association between a relevant task dimension (e.g., colour) and the specific response. A third possibility would relate to the involvement of regions held to be responsible for holding a task-set for later execution, proposed to be more anteriorly located on the medial surface (e.g., Haynes et al., 2007). Unfortunately the lesions of the SM group were insufficiently focal within the medial surfaces to determine whether the pre-SMA, the anterior cingulate or indeed yet more anterior structures were playing a critical role.

\section{The higher error rates in the inferior medial group}

The IM group had a significantly higher overall error rate than the CTLs in the combined Long Cue and the Short Cue conditions.. The more specific anatomical analysis pointed to left areas $110,14 \mathrm{~m}$ and $47 / 120$ in addition to left area $9 \mathrm{~s}$, as showing a higher rate of errors at the 0.05 level or more. In imaging studies, it has been shown that a variety of regions of IM prefrontal cortex are activated when the amount of gain or loss is manipulated when making a correct or an error response (e.g., Taylor et al., 2006). Moreover, patients with orbital lesions show much higher error rates in memory tasks where category cues are used (Turner et al., 2007). IM lesions might therefore be expected to lead to a reduction in the implicit cost to the subject in making an error (see e.g., Rolls, 2004).
The subject cares less. Task switching is a highly attention-demanding task where any lapsing into an automatic mode of responding is liable to lead to an error particularly on a switch trial, so a reduction in the implicit cost of making an error is likely to lead to an increase in their occurrence. At the same time such a tendency to move to a more automatic mode of responding would be expected to lead to a reduction in switch costs; this indeed occurs in the IM group.

\section{The left lateral effect on errors}

Even though there were no differences in the performance of the LL group and that of the CTL Group on reaction times, there was a LL effect on errors in our study. The LL group showed a significantly greater number of errors than the controls in the first block of each condition they carried out by comparison with the second block, which involved precisely the same condition. Thus they were as bad as the worst other frontal group - the IM group - on the very first block and yet were almost identical to the CTL Group on the very last one. A similar effect of a greater number of errors on their blocks 1 and 2 in Left Frontal patients by comparison with CTL subjects and Right Frontal patients appears as a 0.07 trend in the results of the task-switching study of Rogers et al. (1998), which had considerably fewer patients. In the current study the more detailed anatomical analysis pointed to left area $9 / 46 \mathrm{v}$.

These effects can be explained in terms of the involvement of the LL region in a process which Stuss et al. (1995) called 'task-setting'. In task-switching a complex set of action-schemas must first be specified so that they can be explicitly realised; the simplest possible set we have been able to produce for the current paradigm is given in Appendix 1 . This process of action schema-specification was called the use of IfThen logic in Stuss et al. (1995). When this has been done, the set of new (perceptual) trigger $\geq$ (action) schema pairs, must begin to be more automated, in the sense that the production of the schema output given that the input conditions are satisfied would come to no longer require conscious inferences or explicit retrieval from episodic memory. (This is equivalent to its being laid down in contention scheduling on the NormanShallice model). In addition to the forming of these new trigger-schema pairs and making their operation fluent, the schemas need to be modulated in the learning period; for instance, over how long the inhibition operates in the last two of the schemas listed above. Determination of the length of the period is itself a complex process considered in the previous section of the Discussion.

The group which was slow to learn to automate these newly required schemas was the LL group. In the first block they made a high numbers of errors in the difficult Short Cue condition. However, the performance of the group became essentially normal after the initial block was completed. In an earlier five-choice serial reaction time task (Alexander et al., 2005), patients with LL lesions showed a similar effect. They performed completely comparably with controls with respect to both reaction time and errors after the first hundred trials, but they had a much higher error rate on the first hundred trials. Thus, in a quite different type of reaction time test, one has a parallel result to that in the Alexander et al., study and so converging evidence for the involvement of the left lateral prefrontal cortex in task-setting. This position is also compatible with the perspective of Brass and von Cramon (2004) derived from related functional imaging experiments in which they found activation of the left inferior frontal gyrus. The difficulty the LL group have is very broadly in accord with problems for left frontal patients found in other smaller studies of task-switching (Keele and Rafal, 2000; Mecklinger et al., 1999; Rogers et al., 1998; Stablum et al., 1994). In particular, the account given has a conceptual similarity and fits very well anatomically with the interpretation given by Aron et al., for the left frontal effects they found and which they associated with the left middle frontal gyrus in their very different task-switching paradigm, namely that left frontal lesions led to weaker endogenous control of task-set (see also Garavan et al., 2002). 


\section{CONCLUSIONS}

Overall the current study supports the position that many different prefrontal processes affect the performance of task-set switching. In addition the study provides converging evidence with a number of other studies (see Stuss and Alexander, 2007) concerning two of these different prefrontal processes. The first such process is the basic energising process which we hold to be required when behaviour cannot just be left to the control of the more automatic contention scheduling processes. Energising appears to be involved in all reaction time tasks but it would be expected to become increasingly critical as the processes involved in the stimulus-response mapping become more complex. Energising is impaired by superior medial prefrontal lesions and the impairment in this group is greater the more complex the stimulus-response mapping. Whether this explanation for the SM group's performance is to be preferred to, or indeed is compatible with, the alternative of a loss of the capacity for monitoring response conflict, remains to be investigated.

A second set of processes, which are required in task-switching, come into play when the block involves competing tasks, each of which can operate on the stimuli presented. Such a situation predisposes the participant to make a capture error in which the wrong task-set controls the response output. Inferior medial lesions lead to higher error rates in both the Long Cue and Short Cue situations. These could possibly be explained in terms of a failure to maintain a sufficiently high criterion to catch potential errors, due to the loss in implicit cost in producing errors.

Finally a third prefrontal region - the left lateral one - is involved in the early stages of learning the task. A similar finding was obtained for performance on the first 100 trials of a 5 -choice serial reaction time study (Alexander et al., 2005). We consider the process impaired to involve 'task-setting' (Stuss et al., 1995), the process involved in setting the stimulus-response contingencies which will control routine behaviour later in task execution. A related position was advocated by Aron et al., to explain somewhat different phenomena related to left frontal lesions in their task-switching paradigm. Overall it is clear, as proposed in Stuss et al. (1995) that there are a variety of processes involved in attentional tasks which are carried out in different regions of prefrontal cortex. Moreover the task-switching paradigm, far from being a process-pure procedure, involves at least three and very likely more anterior attentional processes.

\section{APPENDIX}

In the current experiment, a set of schemas at least as complex as the following ones must be set up by the cognitive system in order to carry out the Meiran task-switching paradigm (an IF/THEN notation is used where the left-hand (IF) side corresponds to both (1) the output of the perceptual system and (2) the equivalent of the contents of a production system working memory (WM), and the right-hand (THEN) side corresponds to operations, with the contents of brackets referring to 'arguments' (i.e., the variables that are set):

\section{IF Cue THEN read text}

2. IF Stimulus present and text 'upper or lower' THEN attend (vertical) in WM

3. IF Stimulus present and text 'left or right' THEN attend (horizontal) in WM

4. IF attend (vertical) is in WM and Square is high THEN press button (L)

5. IF attend (vertical) is in WM and Square is low THEN press button (R)

6. IF attend (horizontal) is in WM and Square is left THEN press button (L)

7. IF attend (horizontal) is in WM and Square is right THEN press button (R)

8. IF instruction (Long Cue condition) THEN Inhibit outputs of schemas $(4,5,6,7)$ but only until a short time after stimulus onset)

9. IF instruction (Short Cue condition) THEN Inhibit outputs of schemas $(4,5,6,7)$ but for a longer period after stimulus onset)

Some process similar to schemas 8 and 9 is required to overcome the effects on schemas 4-7 of task-set inertia (i.e., the continuing activation of schemas from the previous trial). The most difficult condition, which is the Short Cue one, must rely heavily on schema 9 to overcome these priming effects.

\section{CONFLICT OF INTEREST STATEMENT}

The authors declare that the research was conducted in the absence of commercial or financial relationships that could be construed as potential conflict of interest.

\section{ACKNOWLEDGEMENTS}

This research discussed in this paper was supported by grants MT-12853 and GR-14974 from the Canadian Institutes for Health Research. Two of the authors are supported by University of Toronto/Baycrest Chairs: T. W. Picton by the Anne and Max Tanenbaum Chair in Cognitive Neuroscience, and D. T. Stuss by the Reva James Leeds Chair in Neuroscience and Research Leadership. M. P. Alexander receives support from the Posluns Centre for Stroke and Cognition at Baycrest Centre and the Heart and Stroke Foundation of Ontario Centre for Stroke Recovery. Malcolm Binns provided advice on the statistical analysis. Many different clinicians referred patients for testing: D. Katz, D. Izukawa, and M. Mountain. Many research assistants and students helped to take the measurements from the patients: N. Arzumanian, S. Bisschop, B. Boucher, D. Derkzen, D. Floden, R. MacDonald and A. Savas.

\section{REFERENCES}

Alexander, M. P., Stuss, D. T., Shallice, T., Picton, T. W., and Gillingham, S. (2005). Impaired concentration due to frontal lobe damage from two distinct lesion sites. Neurology $65,572-579$.

Allport, D. A., Styles, E. A., and Hsieh, S. (1994). Shifting intentional set: exploring the dynamic control of tasks. In Attention and Performance XV, C. Umilta, and M. Moscovitch, eds (Cambridge, MA, MIT Press), pp. 421-452.

Allport, D. A., and Wylie, G. (2000). "Task-switching", stimuli-response bindings, and negative priming. In Attention and Performance XVIIl: Control of Cognitive Processes, S. Monsell, and J. S. Driver, eds (Cambridge, MA, MIT Press), pp. 35-70.

Altmann, E. M. (2004). Advance preparation in task switching: what work is being done? Psychol. Sci. 15, 616-622.

Altmann, E. M. (2005). Repetition priming in task switching: do the benefits dissipate? Psychon. Bull. Rev. 12, 535-540.

Aron, A. R., Fletcher, P. C., Bullmore, E. T., Sahakian, B. J., and Robbins, T. W. (2003) Stop-signal inhibition disrupted by damage to right inferior frontal gyrus in humans. Nat. Neurosci. 6, 1329.

Aron, A. R., Monsell, S., Sahakian, B. J., and Robbins, T. W. (2004). A componential analysis of task-switching deficits associated with lesions of left and right frontal cortex. Brain 127, 1561-1573.

Aron, A. R., and Poldrack, R. A. (2006). Cortical and subcortical contributions to stop signal response inhibition: role of the subthalamic nucleus. J. Neurosci. 26, 2424-2433.

Bates, E., Wilson, S. M., Saygin, A. P., Dick, F., Sereno, M. I., Knight, R. T., and Dronkers, N. F. (2003). Voxel-based lesion-symptom mapping. Nat. Neurosci. 6, 448-450.

Biederman, I. (1972). Human performance in contingent information-processing tasks. J. Exp. Psychol. 93, 219-238.

Botvinick, M., Nystrom, L. E., Fissell, K., Carter, C. S., and Cohen, J. D. (1999). Conflict monitoring versus selection-for-action in anterior cingulate cortex. Nature 402 , 179-181.

Brass, M., Ruge, H., Meiran, N., Rubin, O., Koch, I., Zysset, S., Prinz, W., and von Cramon, D. Y. (2003). When the same response has different meanings: recoding the response meaning in the lateral prefrontal cortex. Neuroimage 20 , 1026-1031.

Brass, M., and von Cramon, D. Y. (2004). Selection for cognitive control: a functional magnetic resonance imaging study on the selection of task-relevant information. J. Neurosci. 24, 8847-8852.

Braver, T. S., Reynolds, J. R., and Donaldson, D. I. (2003). Neural mechanisms of transient and sustained cognitive control during task switching. Neuron 39, 713-726.

Burgess, P. W., and Shallice, T. (1996). Response suppression, initiation and strategy use following frontal lobe lesions. Neuropsychologia 34, 263-272.

Carter, C. S., Braver, T. S., Barch, D. M., Botvinick, M. M., Noll, D., and Cohen, J. D. (1998). Anterior cingulate cortex, error detection, and the online monitoring of performance. Science 280, 747-749.

Chambers, C. D., Bellgrove, M. A., Stokes, M. G., Henderson, T. R., Garavan, H., Robertson, I. H., Morris, A. P., and Mattingley, J. B. (2006). Executive "brake failure" following deactivation of human frontal lobe. J. Cogn. Neurosci. 18, 444-455.

Damasio, H., and Damasio, A. R. (1989). Lesion Analysis in Neuropsychology. New York, NY, Oxford University Press. 
De Jong, R. (2000). An intention-activation account of residual switch costs. In Control of Cognitive Processes: Attention and Performance XVIII, S. Monsell, and J. Driver, eds (Cambridge, MA, MIT Press), pp. 357-376.

DiGirolamo, G. J., Kramer, A. F., Barad, V., Cepeda, N. J., Weissman, D. H., Milham, M. P., Wszalek, T. M., Cohen, N. J., Banich, M. T., Webb, A., et al. (2001). General and task-specific frontal lobe recruitment in older adults during executive processes: a fMRI investigation of task-switching. Neuroreport 12, 2065-2071.

Dove, A., Pollmann, S., Schubert, T., Wiggins, C. J., and von Cramon, D. Y. (2000) Prefrontal cortex activation in task switching: an event-related fMRI study. Cogn. Brain Res. 9, 103-109.

Dreher, J. C., and Berman, K. F. (2002). Fractionating the neural substrate of cognitive control processes. Proc. Natl. Acad. Sci. U.S.A. 99, 14595-14600.

Dreher, J. C., Koechlin, E., Ali, S. 0., and Grafman, J. (2002). The roles of timing and task order during task switching. Neuroimage 17, 95-109.

Dreisbach, G., Haider, H., and Kluwe, R. H. (2002). Preparatory processes in the taskswitching paradigm: evidence from the use of probability cues. J. Exp. Psychol. Learn. Mem. Cogn. 28, 468-483.

Elsass, P., and Hartelius, H. (1985). Reaction time and brain disease: relations to location, etiology and progression of cerebral dysfunction. Acta Neurol. Scand. 71, $11-19$.

Garavan, H., Ross, T. J., Murphy, K., Roche, R. A., and Stein, E. A. (2002). Dissociable executive functions in the dynamic control of behavior: inhibition, error detection and correction. Neuroimage 17, 1820-1829.

Gilbert, S. J., and Shallice, T. (2002). Task switching: a PDP model. Cognit. Psychol. 44 297-337.

Haynes, J. D., Sakai, K., Rees, G., Gilbert, S., Frith, C., and Passingham, R. E. (2007). Reading hidden intentions in the human brain. Curr. Biol. 17, 323-328.

Jersild, A. T. (1927). Mental set and shift. Arch. Psychol. 89, 81.

Keele, S. W., and Rafal, B. (2000). Deficits of attentional set in frontal patients. In Contro of Cognitive Processes: Attention and Performance XVIII, S. Monsell, and J. S. Driver eds (Cambridge, MA, MIT Press), pp. 627-651.

Keppel, G. (1982). Design and analysis. Englewood Cliffs, NJ, Prentice Hall.

Logan, G. D., and Bundesen, C. (2003). Clever homunculus: is there an endogenous act of control in the explicit task-cuing procedure? J. Exp. Psychol. Hum. Percept. Perform. 29, 575-599.

MacDonald, A. W., Cohen, J. D., Stenger, V. A., and Carter, C. S. (2000). Dissociating the role of the dorsolateral prefrontal and anterior cingulate cortex in cognitive control. Science 288, 1835-1838.

Mecklinger, A. D., von Cramon, D. Y., Springer, A., and Matthes-von Cramon, G. (1999) Executive control functions in task switching: evidence from brain injured patients. J. Clin. Exp. Neuropsychol. 21, 606-619.

Meiran, N. (1996). Reconfiguration of processing mode prior to task performance. J. Exp. Psychol. Learn. Mem. Cogn. 22, 1432-1442.

Meiran, N., Chorev, Z., and Sapir, A. (2000). Component processes in task switching. Cognit. Psychol. 41, 211-253.

Meiran, N., and Daichman, A. (2005). Advance task preparation reduces task error rate in the cuing task-switching paradigm. Mem. Cogn. 33, 1272-1288.

Meiran, N., and Gotler, A. (2001). Modelling cognitive control in task switching and ageing. Eur. J. Cogn. Psychol. 13, 165-186.

Milner, B. (1963). Effects of different brain lesions on card sorting: the role of frontal lobes. Arch. Neurol. 9, 90-100.

Monsell, S. (2003). Task switching. Trends Cogn. Sci. 7, 134-140.

Monsell, S. \& Mizon, G. A. (2006). Can the task-cuing paradigm measure an endogenous task-set reconfiguration process. J. Exp. Psychol. Hum. Percept. Perform. 32, 493-516.

Mottaghy, F. M., Willmes, K., Horwitz, B., Muller, H. W., Krause, B. J., and Sturm, W. (2006). Systems level modeling of a neuronal network subserving intrinsic alertness. Neuroimage 29, 225-233.

Norman, D. A., and Shallice, T. (1986). Attention to action: willed and automatic contro of behaviour. In Consciousness and Self-regulation: Advances in Research, Vol. IV R. J. Davidson, G. E. Schwartz, and D. Shapiro, eds (New York, NY, Plenum Press), pp. 1-18.

Owen, A. M., Downes, J. J., Sahakian, B. J., Polkey, C. E., and Robbins, T. W. (1990). Planning and spatial working memory following frontal-lobe lesions in man. Neuropsychologia 28, 1021-1034.

Petrides, M., and Pandya, D. N. (1999). Dorsolateral prefrontal cortex: comparative cytoarchitectonic analysis in the human and the macaque brain and corticocortical connection patterns. Eur. J. Neurosci. 11, 1011-1036.
Rogers, R. D., and Monsell, S. (1995). Costs of a predictable switch between simple cognitive tasks. J. Exp. Psychol. Gen. 124, 207-231.

Rogers, R. D., Sahakian, B. J., Hodges, J. R., Polkey, C. E., Kennard, C., and Robbins, T. W. (1998). Dissociating executive mechanisms of task control following frontal lobe damage and Parkinson's disease. Brain 121, 815-842.

Rolls, E. T. (2004). The functions of the orbitofrontal cortex. Brain Cogn. 55, 11-29.

Rorden C., \& Karnath H. 0. (2004). Using human brain lesions to infer function: a relic from a past era in the fMRI age? Nat. Rev. Neurosci. 5, 813-819.

Ruge, H., Brass, M., Koch, I., Rubin, O., Meiran, N., and von Cramon, D. Y. (2005). Advance preparation and stimulus-induced interference in cued task switching: further insights from BOLD fMRI. Neuropsychologia 43, 340-355.

Rushworth, M. F. S., Hadland, K. A., Paus, T., and Sipila, P. K. (2002). Role of the human medial frontal cortex in task switching: a combined fMRI and TMS study. J. Neurophysiol. 87, 2577-2592.

Schweizer, T.A., Oriet, C., Meiran, N., Alexander, M. P., Cusimano, M., and Stuss, D. T. (2007) The cerebellum mediates conflict resolution. J. Cogn. Neurosci. 19, 1974-1982.

Shallice, T. (2003). Functional imaging and neuropsychology findings: how can they be linked? Neuroimage 20, S146-S154.

Sohn, M. H., and Carlson, R. A. (1998). Procedural frameworks for simple arithmetic skills. J. Exp. Psychol. Learn. Mem. Cogn. 24, 1052-1067.

Sohn, M. H., Ursu, S., Anderson, J. R., Stenger, V. A., and Carter, C. S. (2000). The role of prefrontal cortex and posterior parietal cortex in task switching. Proc. Natl. Acad. Sci. U.S.A. 97, 13448-13453.

Spector, A., and Biederman, I. (1976). Mental set and mental shift revisited. Am. J. Psychol. 89, 669-679.

Stablum, F., Leonardi, G., Mazzoldi, M., Umiltà, C., and Morra, S. (1994). Attention and control deficits following closed head injury. Cortex 30, 603-618.

Sturm, W., de Simone, A., Krause, B. J., Specht, K., Hesselmann, V., Radermacher, I., Herzog, H., Tellmann, L., Muller-Gartner, H. W., and Willmes, K. (1999). Functional anatomy of intrinsic alertness: evidence for a fronto-parietal-thalamic-brainstem network in the right hemisphere. Neuropsychologia 37, 797-805.

Stuss, D. T., and Alexander, M. P. (2007). Is there a dysexecutive syndrome? Philos. Trans. R. Soc. Lond. B Biol. Sci. 362, 901-915.

Stuss, D. T. Alexander, M. P. Floden, D., Binns, M. A., Levine, B. Mclntosh, A. R. Rajah, N., and Hevenor, S. J. (2002a). Fractionation and localization of distinct frontal lobe processes: evidence from focal lesions in humans., In Principles of Frontal Lobe Function, D. T. Stuss, and R. T. Knight, eds (New York, NY, Oxford University Press), pp. 392-407.

Stuss, D. T., Binns, M. A., Murphy, K. J., and Alexander, M. P. (2002b). Dissocations within the anterior attentional system: Effects of task complexity and irrelevant information on reaction time speed and accuracy. Neuropsychologia 16, 500-513.

Stuss, D. T., Alexander, M. P., Hamer, L., Palumbo, C., Dempster, R., Binns, M., Levine, B., and Izukawa, D. (1998). The effects of focal anterior and posterior brain lesions on verbal fluency. J. Int. Neuropsychol. Soc. 4, 265-278.

Stuss, D. T., Alexander, M. P., Palumbo, C. L., Buckle, L., Sayer, L., and Pogue, J. (1994). Organizational strategies of patients with unilateral or bilateral frontal lobe injury in word list learning tasks. Neuropsychology 8, 355-373.

Stuss, D. T., Alexander, M. P., Shallice, T., Picton, T. W., Binns, M. A., Macdonald, R, Borowiec, A., and Katz, D. I. (2005). Multiple frontal systems controlling response speed. Neuropsychologia 43, 396-417.

Stuss, D. T., Levine, B., Alexander, M. P., Hong, J., Palumbo, L., Hamer, K. J., Murphy, K. J., and Izukawa, D. (2000). Wisconsin Card Sorting Test performance in patients with focal frontal and posterior brain damage: effects of lesion location and test structure on separable cognitive processes. Neuropsychologia 38, 388-402.

Stuss, D. T., Shallice, T., Alexander, M. P., and Picton, T. W. (1995). A multidisciplinary approach to anterior attentional functions. Ann. N. Y. Acad. Sci. 769, 191-211.

Taylor, S. F., Martis, B., Fitzgerald, K. D., Welsh, R. C., Abelson, J. L., Liberzon, I., Himle, J. A., and Gehring, W. J. (2006). Medial frontal cortex activity and loss-related responses to errors. J. Neurosci. 26, 4063-4070.

Turner, M. S., Cipolotti, L., Yousry, T., and Shallice, T. (2007). Qualitatively different memory impairments across frontal lobe subgroups. Neuropsychologia 45 , 1540-1552.

Walton, M. E., Devlin, J. T., and Rushworth, M. F. S. (2004). Interactions between decision making and performance monitoring within prefrontal cortex. Nat. Neurosci. 7, 1259-1265

Waszak, F., Hommel, B., and Allport, A. (2003). Task-switching and long-term priming: role of episodic stimulus-task bindings in task-shift costs. Cognit. Psychol. 46 , 361-413. 